\title{
Perception of Undergraduates of The Contributions on Online Tools Toward Improvement of Reading Habit in Kwara State Universities
}

\author{
Kabir Alabi Sulaiman \& Mohammed Lawal Akanbi
}

Paper Type: Research Paper

\section{University of Ilorin, Ilorin}

\section{Abstract}

Background of the study: The study aimed at examining perceptions of undergraduates on the contributions of online tools towards improvement of reading habit in Kwara state in universities. The study identified six (6) research questions. The research population was limited to undergraduates at the University of Ilorin, Kwara State University, Malate and Al-Hikmah University. Purpose: The study adopted descriptive survey design with questionnaire to collect data. The simple random sampling technique was adopted. The researcher used Educational and Psychological Measurement Israel model (2003) sample table to arrive at the actual sample size for this study. Therefore, the sample size for this study at level of $\pm 5 \%$ level of significance for population of 53, 130 students was 397 . With total population of $76 \%$ for University of Ilorin, $18 \%$ for Kwara State University Malate and 6\% for Al-Hikmah University, Ilorin.

Method: Data collected from the field were analyzed using descriptive method of analysis.

Findings: The findings of the study revealed that blog, twitters, E-mail, websites, YouTube, Facebook is the most available online tools that improve undergraduates reading habit. The study also revealed that undergraduates using online tools for social purpose than others.

Conclusion: The study concluded that undergraduates have good perception using online tools for their reading. The study also established that undergraduates using online tools for social, political, recreation and religion benefits. It is also established that distraction, fallout from technologies, financial constraints and poor power supply are the major setbacks to the use of online tools for reading.

Keywords: Online tools, ICT, Reading, Reading Habits, Perception. 


\section{Introduction}

The $21^{\text {st }}$ Century has heralded the advent of Information Communication and Technology (ICT). This technology has multifaceted benefits of the activities of various professions, organizations, institutions and other disciplines. These benefits cannot be over-emphasized as it has immense importance to the reading habit of students all over the world. Online tools are modern technologies designed to transmit and store electronic information from one end to the other for better understanding. Online tools need to be embraced by individual, organizations and institutions for an improved reading habit. Tah, (2010) denoted that the impact of online tools in the study is related to the use of electronic media such as a computer that is meant to facilitate teaching and learning.

Ihuoma, (2012) observed that the perception of undergraduates on the contributions of online tools depends on the university environment, field of study and social factors that are inherent within the society of students. Feldman (2005) noted that perception is the organization, sorting, interpretation, analysis and integration of stimuli carried out by the sense organs and brain. The belief that online tools improve students' reading habit could form the basis of the perception among undergraduates' in universities to their reading culture. Consequently, in respect to this study, the perception is referred to as undergraduate students' way of life, attitudes, opinions, and ways of thinking and mind-set towards the contributions of online tools to their improvement in reading.

Samali, Humphrey, Clive and Kehbuma, (2015) observed that reading is a formal process of making sense from printed and written words for the pursuit of academic success. Ozbay, (2006) noted that" a black American activist and bookseller who lived between 1884-1976) once said the best way to hide a thing for a black man is to put it in the book." Reading is more than just take a book and read it for day-to-day activities; it is about making reading part of one, which led to the concept of reading habit. Issa, Amusan, Adeniran and Bolarinwa, (2014) stressed that reading is a dynamic effort of readers to develop an understanding of writer message and the art of deducing the main content of printed and the written word in order to communicate new information and knowledge among students.

Haliru, Abdulkareem, Mohammed and Dangani (2015) observed that reading habits is the behavior which expresses the liking for reading of individual types and tastes for reading, i.e is a pattern in which individual organizes its reading. Satija (2002) is of opinion that when students develop the habit of reading mental horizon and opportunities are developed. Hetting and Knapp, (2001) noted that reading habit is important to undergraduate, because it is the critical factor that determine the ability of undergraduate to read, understand and comprehend information at disposal. Reading habits are seen as how often, how much, and what students read (Shen, 2006). This means that reading habit is the ability of students to read without being forced at all time.

Therefore, online tools are usually called Information and Communication Technology (ICTs). Bradford (2012) observed that modern technology has reshaped the mind infrastructure of students which enhance reading habit. However, Izabela (2015) stressed that online tools encourage instructional process and facilitates learning process among undergraduate. Siraj-Blatchford and Siraj-Blatchford (2003) observed that online tools are anything that enable undergraduate to have access to information and communicate situation using electronic or digital equipment. Haliru, et al. (2015) opined that reading habits assist undergraduates in crucial thinking of selecting, analyzing, critiquing, and synthesizing with the aid of online tools. Kazim, (2017) noted that the present growth in digital information has changed the way students perceive reading and how online tools have been used to ease study of both students and lecturers. Against this backdrop, this study examined the perception of Kwara state undergraduates on the contribution of online tools toward improvement of the reading habit.

\section{Statement of the Problem}

In the past years of the $20^{\text {th }}$ Century, reading was perceived to be difficult among students to the extent that whosoever passionate with reading will be given names like "iwe, professor, and-book, bookworm" mention but a few. But with the advent of the $21^{\text {st }}$ Century that is heralded as the introduction of ICTs has virtually made students passionate about reading due to the use of various available online 
tools that make studying easier. This includes websites, e-mail, video limes, students' portals, social media and networking sites. Halic, Lee, Paulus and Spence (2010) observed that students found out that blogging influence reading and noted that students with personal blogs were more interested in blogging than students who did not use blogs as an online tool. With benefits of online tools, there is still a notion that undergraduates have poor perception about its use with respect to reading habit. This is so as poor power supply, insufficient financial resources and location are perceived to be seen as factors that affect the use of online tools towards improvement reading habit by undergraduates.

It is also noted that undergraduates depend highly on the use of online tools for reading as researches have shown in the past (Issa, Amusan, Adeniran \&Bolarinwa, 2014). No ICTs or online tools can be successfully used to aid reading among students without stable power supply. For instance, undergraduates use Android phones and other tablets as gadgets to assess online tools for reading, which consume a lot of battery charging and if there is no electricity supply and no access to alternative then reading are disrupted. However, insufficient financial resources in the country are also a challenge to use the online tools as many undergraduates perceived not to have the resources to purchase data and other needed facilities to assess online tools which could improve their reading habit.

It is also perceived that location of students in university becomes a challenge to the use of online tools for improvement of reading. This is because in a situation where the used network for browsing is bad and out of reach, then it becomes a problem. Several studies have been carried out on reading habits of undergraduates in the world, especially on how Information and communication Technology have been able to improved reading habits, but based on the knowledge of the researcher on available literature at his disposal, little have carried been out among undergraduates in Nigeria especially in Kwara State. Against this backdrop, this study examined perceptions of Kwara state undergraduates on the contributions of online toward improvement of the reading habit.

\section{Research Questions}

The following research questions were provided to give the study focus.

1. What are the online tools used for reading by undergraduates in Kwara State universities?

2. What is the undergraduates' perception about the use of online tools towards improvement of reading habit in Kwara State?

3. What are the purposes of reading by undergraduates using online tools in Kwara State?

4. What is frequency of reading amongst undergraduates using online tools in Kwara State?

5. What are the benefits of using online tools for reading by undergraduates in Kwara State?

6. What are the challenges associated with the use of online tools for reading by undergraduates in Kwara State?

\section{Literature Review}

Haliru, Abdulkarim, Mohammed and Danganim, (2015) defined reading as an act of translating symbol or letter into word that have significant influence on students. This implies that reading is thoughtful about what is seen as text and visual information which meaning is obtained. According to Chettri and Rout (2013) observed that reading makes way for better understanding of the phenomenon. Kazim, (2017) opined that reading is a way of seeking knowledge, information or entertainment through books, magazines, journals, newspapers and other information resources. This described why university undergraduate students who read wide have a larger knowledge base and always have an edge over those who narrow their reading to a particular type of information material.

Moreover, Ihuoma, (2012) affirmed that reading is the building of meaning from information material in order to comprehend and equip our mind to incorporate new ideas and concept; also to interpret the information and incorporate them into what we already know. Loan, (2011) noted that continues and regular reading improved the intellect, rear the emotions, increase taste and provide perspectives for a meaningful existence among undergraduates students. Ewuzie, (2012) observed that reading enhances the thinking process and expose university students to a wide variety of issues and events; also leading to 
creativity which helps university students to set free in their natural potentials. Palani, (2012) opined that effective reading is an important avenue for due learning in higher institution.

Issa, Amusan, Adeniran and Bolarinwa (2014) examined the perception of undergraduate students in Kwara state on the effects of ICT. Four objectives were identified in the study. The population of the study was undergraduate students in Kwara state. Descriptive survey was used. Frequency table and percentage was used to analyze the data collected. A survey of 5240 respondents comprising $60.13 \%$ male and 39.87 female used for the study. 39 Survey of 5240 respondents comprising $60.13 \%$ male and $39.87 \%$ female was used for the study. The study found out that smart phone, computer, iPad and internet were used for leisure/socializing than academic purposes. The study concluded that library relevance in inculcating good reading habit has been craggy by the influence of ICT. It is shown in the study that the use of ICT has perceived to have a negative impact on the reading habit.

Tah (2010) examined the impact of information and communication technology on students' study habit in Uganda. Two objectives were examined to include students familiarity and students' attitude toward ICT and the relationship between students use of ICT and study habits. The population of the study is undergraduate students at University of Uganda. Descriptive survey was used and the percentage and frequency count was used to analyze the data collected. Three hundred and thirty 332 were randomly selected for the study at the university. The finding of the study revealed that undergraduate students with a positive mind set on the use of ICTs develop reading habit.

Samali, et al (2015) assessed uncovering reading habit of university students in Uganda: Does ICT matters? The study used qualitative phenomenological approach in order to get an in-depth understanding of how ICT phenomenon impacts on reading habits. Participation from four universities in Uganda were interviewed. The findings of the study show that the majority of students find the use of ICT necessary for helping them to have access to reading resources and also ICT influence students to have reading habit in school and home.

Samali, Humphrey, Clive, Kehbuma, Victor and Mayok (2014) investigated the use of ICT and reading habit among university studies in Uganda. Three research questions were raised. A cross sectional analysis was used which captured ICT that influence reading habits from eight universities in Uganda. Correlation and linear regression analysis were run and t-test was used for the hypotheses formulated. The finding of the study revealed that ICT usage influence reading habits of students in Uganda universities.

Akarsu and Dariyemez (2014) examined reading habit of university students studying English Language and Literature in the digital age in Suwaill. The study was to determine the effects of widespread use of internet and other alternative multimedia resources for reading habit. Seventy six undergraduate students were randomly selected for the study. The questionnaire involves six categories was designed to include demographic information, frequency of items read, content of online activities, content first clicked when online and techniques to develop the reading habit. Percentage and frequency table using SPSS version 20 was to analysis the data collected. The finding of the study revealed that digital tools have a positive influence on reading of students studying English language and literature.

Mohammed Majid, Nalini and Ooichoon (2014) examined the online reading habit of Malaysian students. The purpose of the study was to find out the difference in online reading habit based on gender and accessed the relationship between socio-economic status and online reading habit. Two hundred forty (240) students were randomly selected for the study. The study used quantitative approach. The study found out that majority of students, regardless of gender and socio-economic status had the similar online reading habit and were more inclined toward social media activities than academic activity.

Eta, Atarere and Rotua (2015) examined impacts of Information and Communication Technology usage on students study habits in the department of Business Education, Delta State College of Education. Two research questions were raised. The study adopted survey research method. The sample size of 100 students was randomly selected from the department. Frequency count and percentage was used to analysis the data collected. The study shows that the majority of students the use of ICT has an influence on students academic performance.

Ajayi, Shorunke and Aboyade (2014) examined the influence of electronic resource use of students 
reading culture in Adeleke University Ede, Osun State. Three research questions were raised. The study used the descriptive survey method with target population of 705 students of Adeleke University. A random sampling method was used to select a sample size of 220 students. A total of 220 copies of questionnaire was administered and 212 copies were returned and found valid in the analysis. Frequency count and percentage was used to analysis the data. It was found out that electronic information resources have an influence on reading habits of students.

\section{Conceptual Model}

This study examined perceptions of undergraduates on the contributions of online tools towards improvement of reading habits in Kwara state. Use of online tool is the dependent variable for this study while perception of students, frequency of reading, the purpose of reading, benefits of reading and challenges are independent variables. The model explained that online tools offer economical benefits for students to expand their research and learning beyond geographical boundaries and has the potential to open doors to information as infinite.

This conceptual model predicts that perception of students can affect the use online tools for improvement of the reading habit. This implies that when students are having good will about online tools, reading habits can be improved. The conceptual model also predicts that the frequency and purposes reading can be influenced by the use of online tools. This described that the use of online tools by undergraduates can make them persistently read. The conceptual model also predicts that benefits and challenges associated with the use of online tools can have negative of positive effect on reading habits of students.

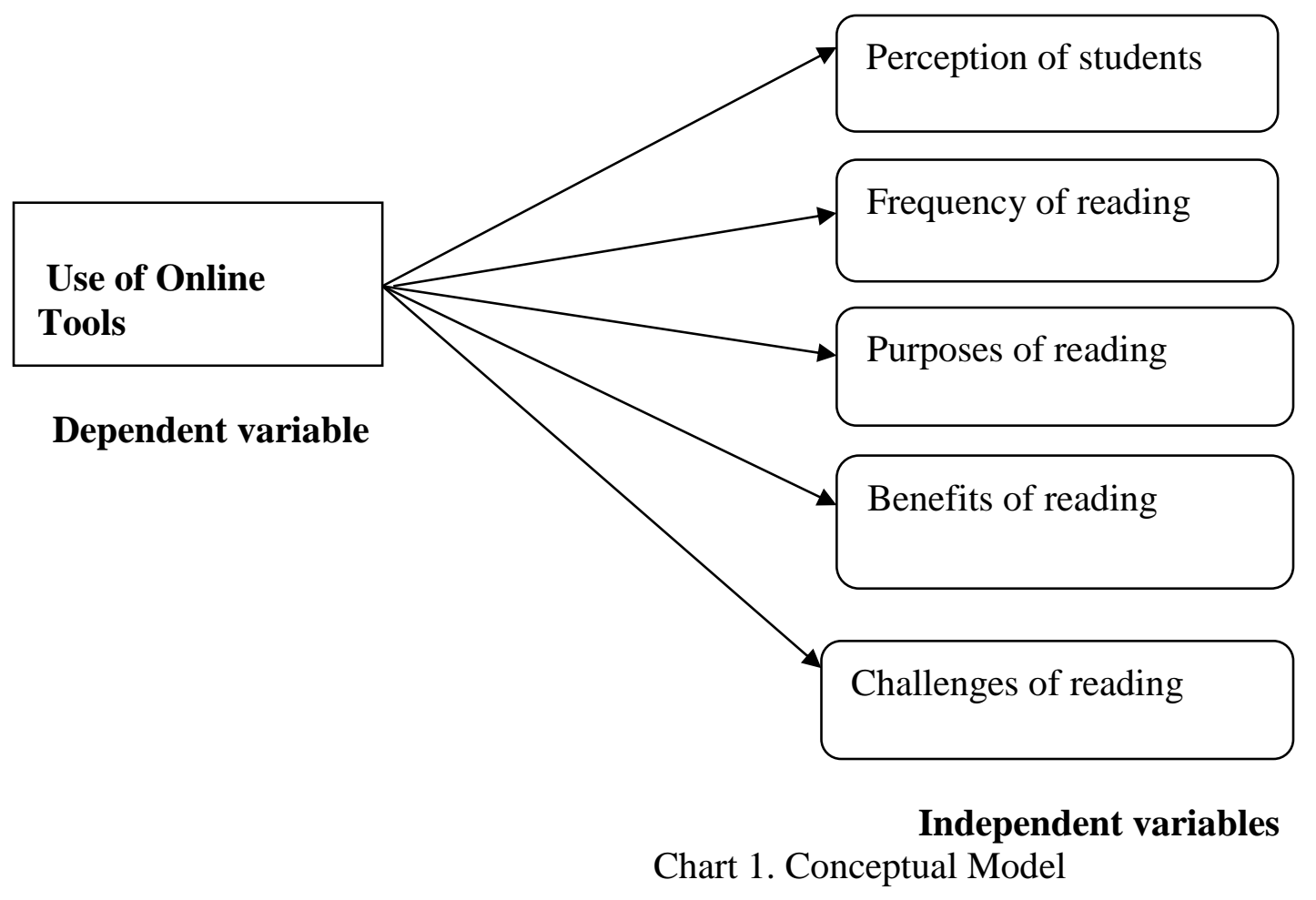

Source: Self diagram Model (2020)

\section{Research Method}

This study investigated the perception of Kwara State undergraduates on the contributions of online tools towards improvement of reading habits. Descriptive survey was adopted to examine 
perceptions of Kwara State undergraduates on the contributions of online tools towards improvement of reading habits. Descriptive survey is used to gather opinion and view of a particular object and condition in a similar circumstance. The population of the study comprising undergraduate of University of Ilorin, Kwara state university Malate and Al-Hikmah University. Therefore, the population for this study is 53,130 students from the three (3) selected universities. The simple random sampling technique was adopted as it gives every respondent equal chance of being selected for the study. The study used Educational and Psychological Measurement Israel model (2003) sample table to arrive at the actual sample size for this study.

Therefore, the sample size for this study at level of $\pm 5 \%$ level of significance for population of 53, 130 students was 397. With total population of 76\% for University of Ilorin, $18 \%$ for Kwara State University Malate and 6\% for Al-Hikmah University, Ilorin. The breakdown of the sample size selection is shown below. This method was supported by Issa et al (2014). The study used self-designed questionnaire titled "Perception of Undergraduates on the Contributions of Online Tools Towards Improvement of Reading Habits in Kwara State (QPKSUCOTIRH)". Descriptive statistics of simple percentage and frequency count was used owing to its simplicity and ease of understanding.

Table 1. Distribution on Study Population

\begin{tabular}{lll}
\hline $\mathbf{S} / \mathbf{N}$ & Name of the University & Total number \\
\hline $\mathbf{1}$ & University of Ilorin, Ilorin & 40,609 \\
$\mathbf{2}$ & Kwara State University, Malete & 9,632 \\
$\mathbf{3}$ & Al-Hikmah University, Ilorin & 2,889 \\
Total & & $\mathbf{5 3 , 1 3 0}$ \\
\hline
\end{tabular}

\section{Source: University's Academic Planning Office}

Table 2. Sample size

\begin{tabular}{llll}
\hline $\mathbf{S} / \mathbf{N}$ & Name of the University & Percentage seler & Sample si: \\
\hline $\mathbf{1}$ & University of Ilorin, Ilorin & $76 / 100 * 397$ & 301 \\
$\mathbf{2}$ & Kwara State University, Ma & $18 / 100 * 397$ & 71 \\
$\mathbf{3}$ & A-Hikmah University, Ilori & $6 / 100 * 397$ & 25 \\
Total & & $\mathbf{5 3 , 1 3 0}$ & $\mathbf{3 9 7}$ \\
\hline
\end{tabular}

\section{Source: Author Field work, 2020}

\section{Data Analysis and Presentation}

This section deals with the results of data collected from the study. The results were based on the variables focused on the study. Out of the three hundred and ninety seven (397) copies of the questionnaire distributed and only three hundred and eighty six (386) copies of the questionnaire was returned and found useable with $97 \%$ return rate as presented below.

Table 3. Demographic Information of Respondents

\begin{tabular}{lll}
\hline Age & Frequency & Percentage \\
\hline $15-20$ & 186 & $48.2 \%$ \\
$21-25$ & 170 & $44.0 \%$ \\
$26-30$ & 30 & $7.8 \%$ \\
$31-35$ & - & - \\
36 years and above & - & - \\
Total & $\mathbf{3 8 6}$ & $\mathbf{1 0 0}$ \\
\hline
\end{tabular}




\begin{tabular}{lll}
\hline Gender & Frequency & Percentage \\
Male & 132 & $34.2 \%$ \\
Female & 254 & $65.8 \%$ \\
Total & $\mathbf{3 8 6}$ & $\mathbf{1 0 0}$ \\
Marital status & Frequency & Percentage \\
Single & 258 & $92.7 \%$ \\
Married & 28 & $7.3 \%$ \\
Total & $\mathbf{3 8 6}$ & $\mathbf{1 0 0}$ \\
Level & Frequency & Percentage \\
100 level & 173 & $44.8 \%$ \\
200 level & 144 & $37.3 \%$ \\
300 level & 55 & $14.5 \%$ \\
400 level & 33 & $3.4 \%$ \\
500 level & - & - \\
Total & $\mathbf{3 8 6}$ & $\mathbf{1 0 0}$ \\
\hline
\end{tabular}

Source: Field Survey (2020)

Table 3 presents the demographic information of the respondents and it shows that $186(48.2 \%)$ of the respondents were between 15-20 years of age. 170 (44.0\%) of the respondents were between 21-25 years of age, while $30(7.8 \%)$ of the respondents were between $26-30$ years of age and $0(0 \%)$ of respondents were between 31 years and above. This indicates that the majority of respondents were between 15-20 years of age. On the response to the gender of respondents 132 (32.2\%) of the respondents were male and $254(65.8 \%)$ of the respondents were female. This shows that the majority of respondents were female.

On the response to the marital status with 258 (92.7\%) of the respondents were single and 28 (7.3\%) of the respondents have married. This shows that the majority of respondents were single respondents and on the response to the years of study of respondent, 173 (44.8\%) of the respondents were at 100 levels, $144(37.3 \%)$ of the respondents were at 200 levels while $55(14.5 \%)$ of the respondents were at 300 levels and $33(3.4 \%)$ of the respondents were at 4 levels. This shows that the majority of respondents were at 100 levels.

\section{Discussion}

Table 4. Online Tools Used By Undergraduates' For Reading In Kwara State Universities?

\begin{tabular}{lllll}
\hline Online Tool: & SA & A & D & SD \\
\hline Videos & $154(39.9 \%)$ & $188(48.7 \%)$ & $29(7.5 \%)$ & $15(3.9 \%)$ \\
Websites & $188(48.7 \%)$ & $169(43.8 \%)$ & $29(7.5 \%)$ & - \\
Facebook & $129(33.4 \%)$ & $236(61.1 \%)$ & $5(1.3 \%)$ & $16(4.1 \%)$ \\
Blog & $347(89.9 \%)$ & $22(5.7 \%)$ & $2(0.5 \%)$ & $15(3.9 \%)$ \\
Twitters & $168(43.5 \%)$ & $140(36.3 \%)$ & $64(16.6 \%)$ & $14(3.6 \%)$ \\
You tubes & $154(39.9 \%)$ & $189(49.0 \%)$ & $29(7.5 \%)$ & $14(3.6 \%)$ \\
E-mail & $188(48.7 \%)$ & $154(39.9 \%)$ & $17(4.4 \%)$ & $27(7.0 \%)$ \\
Portal & $79(20.5 \%)$ & $123(31.9 \%)$ & $130(33.7 \%)$ & $54(14.0 \%)$ \\
Networking 5 & $104(26.9 \%)$ & $146(37.8 \%)$ & $84(21.8 \%)$ & $52(13.5 \%)$ \\
\hline
\end{tabular}

Source: Field Survey (2020)

Note: SA: Strongly agree, A: Agree, Disagree, SD: Strongly disagree

Table 4 show's respondents on online tools available for reading with $154(39.9 \%)$ of the respondents were strongly agreed with videos, 188 (48.7\%) of the respondent were agreed while $29(7.5 \%)$ of the respondents were disagreed and $15(3.9 \%)$ of the respondents strongly disagreed with using of videos for reading. This show that the majority of respondents agreed with use of videos for reading. A 
majority of 188 (48.7) of the respondents strongly agreed with websites as online tools, $169(43.8 \%)$ of the respondent agreed while $29(7.5 \%)$ of the respondents disagreed. The table also shows that 129 (33.4\%) of the respondent strongly agreed with Facebook as online tools, $236(61.1 \%)$ of the respondent agreed while $5(1.3 \%)$ of respondents disagreed and $16(4.1 \%)$ of the respondent strongly disagreed. This indicates that the majority of respondents agreed with Facebook as an online tool for reading.

However, the majority of $347(89.9 \%)$ of the respondents strongly agreed to blog, $22(5.7 \%)$ of the respondents agreed while $2(0.5 \%)$ of the respondents disagreed and $15(3.9 \%)$ of the respondents strongly disagreed. On the $168(43.5 \%)$ of the respondents strongly agreed with twitters as an online tool for reading, $140(36.3 \%)$ of the respondents agreed while $64(16.6 \%)$ of the respondents disagreed and 14 (3.6\%) of the respondents strongly disagreed. This indicates that majority of agreed with twitters as a tool for reading. In 154 (39.9\%) of the respondents strongly agreed with You tubes, 189 (49.0\%) of the respondents agreed while $29(7.5 \%)$ of the respondents disagreed and $14(3.6 \%)$ of the respondents strongly disagreed. A majority $188(48.7 \%)$ of the respondents strongly agreed with E-mail as an online tool for reading, $154(39.9 \%)$ of the respondents agreed while 17 (4.4\%) of the respondents disagreed and $27(7.0 \%)$ of the respondent strongly disagreed.

Furthermore, few $79(20.5 \%)$ of the respondents strongly agreed with the portal as online tools, $123(31.9 \%)$ of the respondents agreed while $130(33.7 \%)$ of the respondents and $54(14.0 \%)$ of the respondents strongly disagreed. This shows that the majority of respondents disagreed with the portal as a tool for reading. Of the $104(26.9 \%)$ respondents strongly agreed with networking sites as a tool for reading, $146(37.8 \%)$ of the respondent agreed while $84(21.8 \%)$ of the respondent disagreed and 52 $(13.5 \%)$ of the respondents strongly disagreed. This indicates that the majority of respondents agreed with availability of blog, videos, websites, Facebook, twitters, e-mail, You tubes of as an online tool for reading and networking and portal was not available to undergraduates for reading.

Table 5. Perception of Undergraduates With Use Of Online Tools Toward Improvement Of Reading In Kwara State

\begin{tabular}{lllll}
\hline Perception & V. Good & Good & V. Poor & Poor \\
\hline Videos & $295(76.4 \%)$ & $73(18.9 \%)$ & $17(4.4 \%)$ & $1(0.3 \%)$ \\
Websites & $212(54.9 \%)$ & $155(40.2 \%)$ & $16(4.1 \%)$ & $3(0.8 \%)$ \\
Facebook & $236(61.1 \%)$ & $129(33.4 \%)$ & $16(4.1 \%)$ & $5(1.3 \%)$ \\
Blog & $226(58.5 \%)$ & $88(22.8 \%)$ & $71(18.4 \%)$ & $1(0.3 \%)$ \\
Twitters & $123(31.9 \%)$ & $130(33.7 \%)$ & $79(20.5 \%)$ & $54(14.0 \%)$ \\
You tubes & $347(89.9 \%)$ & $22(5.7 \%)$ & $2(0.5 \%)$ & $15(3.9 \%)$ \\
E-mail & $242(62.7 \%)$ & $90(23.3 \%)$ & $40(10.4 \%)$ & $10(3.6 \%)$ \\
Portal & $15(3.9 \%)$ & $29(7.5 \%)$ & $188(48.7 \%)$ & $154(39.9 \%)$ \\
\hline
\end{tabular}

Source: Field survey (2020)

Table 5 shown responses on the distribution on the perception of undergraduates in the use of online tools with 368 (95.3) of respondent have good perception on videos as an online tool while 18 (4.7\%) of respondents have poor perception on videos. The table also shown that $367(95.1 \%)$ of respondents have good perception about websites as an online tool while 19 (4.9\%) of respondents have poor perception. It is also shown in the table that $365(95.5 \%)$ of respondents have a good perception about Facebook as an online tool while $21(5.0 \%)$ of respondents have poor perception.

Further, it is also observed that $314(81.3 \%)$ of respondents have good perception about the blog as blog while $72(18.7 \%)$ of respondents have poor perception. The table also that $253(65.6 \%)$ of respondents have good perception about Twitters as an online tool while 133 (34.4\%) of respondents have poor perception. It is also revealed in the table that $369(96.6 \%)$ of respondent have good perception on YouTube as an online tool while 17 (3.4\%) of respondent have poor perception. Table 3 also shows that 
$332(86.0 \%)$ of respondent have good perception about E-mail while $50(14.0 \%)$ of respondents have poor perception. Lastly, $44(11.4 \%)$ of respondent have good perception on portal and $342(88.6 \%)$ of respondents have poor perception about portal as an online tool. The implication of this table to the table is that the majority of respondents have good perception on videos, websites, blog, Twitters, You-tubes and E-mail as online tools. This implies that undergraduates' in Kwara State have a very good perception about available online tools that could improve the reading habit of students.

Table 6. Purpose Of Using Online Tools For Reading By Undergraduates In Kwara State Universities

\begin{tabular}{lllll}
\hline Purpose & SA & A & D & SD \\
\hline Examination & $67(17.4 \%)$ & $70(18.1 \%)$ & $195(50.5 \%)$ & $54(10.0 \%)$ \\
Recreation & $166(43.0 \%)$ & $161(41.7 \%)$ & $14(11.4 \%)$ & $15(3.9 \%)$ \\
Religion & $220(57.0 \%)$ & $91(23.6 \%)$ & $60(15.5 \%)$ & $15(3.9 \%)$ \\
Political & $226(58.5 \%)$ & $88(22.8 \%)$ & $71(18.4 \%)$ & $1(0.3 \%)$ \\
Economic & $172(44.6 \%)$ & $157(40.7 \%)$ & $43(11.1 \%)$ & $14(3.6 \%)$ \\
Social purposi & $295(76.4 \%)$ & $73(18.9 \%)$ & $17(4.4 \%)$ & $1(0.3 \%)$ \\
Personal deve & $90(23.3 \%)$ & $242(62.7 \%)$ & $40(10.4 \%)$ & $10(3.6 \%)$ \\
\hline
\end{tabular}

Source: Field Survey (2020)

Note: SA: Strongly agree, A: Agree, Disagree, SD: Strongly disagree

Table 6 shows the response to the purpose of using online tools for reading by undergraduates in Kwara State Universities with 67 (17.4\%) of respondents strongly agreed that undergraduate use online tools for examination, $70(18.1 \%)$ of the respondents agreed while $195(50.5 \%)$ of the respondents disagreed and $54(10.0 \%)$ of the respondent strongly disagreed. This indicates that majority strongly disagreed that undergraduates' use online tools for examination. On the 166(43.0\%) of the respondent strongly agreed with recreation as purpose for using online tools, $161(41.7 \%)$ of the respondents agreed while $14(11.4 \%)$ of the respondent disagreed and $15(3.9 \%)$ of the respondents strongly disagreed. This is showing that a majority of respondents agreed with recreation as purpose by undergraduate for using online for reading.

However, the majority of $220(57.0 \%)$ of respondents strongly agreed with religion as purpose for using online tools for reading, $91(23.6 \%)$ of the respondents agreed while $60(15.5 \%)$ of the respondents disagreed and 15 (3.9\%) of the respondents strongly disagreed. On the 226 (58.5\%) of the respondents strongly agreed with politically as the purpose of using online tools for reading, $88(22.8 \%)$ of the respondents agreed while $71(18.4 \%)$ of the respondents disagreed and $1(0.3 \%)$ of the respondents strongly disagreed. This shows that the majority of respondents agreed with politically as the purpose of using online tools for reading. A majority $172(44.6 \%)$ of the respondents strongly agreed with economic purpose of using of online for reading, 157 (40.7\%) of respondents agreed while $43(11.1 \%)$ of the respondents disagreed and $14(3.6 \%)$ of the respondents strongly disagreed.

Furthermore, majority 295 (76.4\%) of the respondents strongly agreed with social purpose of using online tools for reading, $73(18.9 \%)$ of the respondents agreed while $17(4.4 \%)$ of the respondents disagreed and $1(0.3 \%)$ strongly disagreed. On the $90(23.3 \%)$ strongly agreed with personal development as the purpose of using of online tools for reading, $242(62.7 \%)$ of the respondents strongly agreed while $40(10.4 \%)$ of the respondents disagreed and 10 (3.6\%) of the respondents strongly disagreed. This indicates that the majority of respondents agreed to use of online tools for recreation, social, religious, economic and political. Though, the majority disagreed that they use online tools for personal development and examination among undergraduates' in Kwara State. 
Table 7: Frequency Of Using Online Tools For Reading

\begin{tabular}{lllll}
\hline Online Tool & Very often & Often & Not often & Rarely \\
\hline Videos & $130(33.7 \%)$ & $123(31.9 \%)$ & $79(20.5 \%)$ & $54(14.0 \%)$ \\
Websites & $189(49.0 \%)$ & $154(39.9 \%)$ & $14(3.6 \%)$ & $29(7.5 \%)$ \\
Facebook & $168(43.5 \%)$ & $140(36.3 \%)$ & $64(16.6 \%)$ & $14(3.6 \%)$ \\
Blog & $347(89.9 \%)$ & $24(6.2 \%)$ & - & $15(3.9 \%)$ \\
Twitters & $188(48.7 \%)$ & $154(39.9 \%)$ & $15(3.9 \%)$ & $29(7.5 \%)$ \\
You tubes & $236(61.1 \%)$ & $129(33.4 \%)$ & $16(4.1 \%)$ & $5(1.3 \%)$ \\
E-mail & $84(21.8 \%)$ & $146(37.8 \%)$ & $104(26.9 \%)$ & $52(13.5 \%)$ \\
Portal & $15(3.9 \%)$ & $29(7.5 \%)$ & $188(48.7 \%)$ & $154(39.9 \%)$ \\
Networking 5 & $29(7.5 \%)$ & $14(3.6 \%)$ & $154(39.9 \%)$ & $189(49.0 \%)$ \\
\hline
\end{tabular}

Source: Field Survey (2020)

Table 7 shows the response to distribution of respondents by frequency of using online tools with $130(33.7 \%)$ of respondents uses videos very often, $123(31.9 \%)$ of respondents uses it often while 79 $(20.5 \%)$ of respondents not often uses it and $54(14.0 \%)$ of respondent rarely use it. $189(49.0 \%)$ of respondents uses websites as online tools very often, $154(39.9 \%)$ of respondents uses it often while 14 (3.6\%) of respondents not often uses it and $29(7.5 \%)$ of respondents rarely uses it. $168(43.5 \%)$ of respondents uses Facebook very often, 140 (36.3\%) of respondents uses it often while $64(16.6 \%)$ of respondents not often and $14(3.6 \%)$ of respondent rarely use it.

Moreover, 347 (89.9\%) of respondents uses blog very often, 24 (6.2\%) of respondent uses it often while $15(3.9 \%)$ of respondent rarely use it. $188(48.7 \%)$ of respondents uses Twitters very often, 154 $(39.9 \%)$ of respondents often uses it while $15(3.9 \%)$ of respondents not often and $29(7.5 \%)$ of respondents rarely uses it. $236(61.1 \%)$ of respondents very often uses YouTube as online tools, 129 $(33.4 \%)$ of respondent often uses it while $16(4.1 \%)$ of respondent not often and $5(1.3 \%)$ of respondents rarely uses it.

Furthermore, $84(21.8 \%)$ of respondents very often uses E-mail as online tools, $146(37.8 \%)$ of respondent often uses it while $104(26.9 \%)$ of respondents not often uses it and $52(13.5 \%)$ of respondents rarely uses it. 15 (3.9\%) of respondents uses Portal as online tool very often, 29 (7.5\%) of respondents uses it often while $188(48.7 \%)$ of respondents not often uses it and 154 (39.9\%) of respondents rarely uses it. $29(7.5 \%)$ of respondents uses networking as online tool very often, 14 (3.6\%) of respondent often uses it while 154 (39.9\%) of respondent not often uses it and 189 (49.0\%) of respondents rarely uses networking as an online tool. The implication of this table shows that majority of respondents use videos, websites, Facebook, blog, twitters, YouTube and e-mail frequently for reading and majority of agreed that they do not use the portal and networking sites for reading as others.

Table 8. Challenges Of Using Online Tools For Reading

\begin{tabular}{rllll}
\hline Challenges & SA & A & D & SD \\
\hline Economic chal & $109(28.2 \%)$ & $203(52.6 \%)$ & $31(8.0 \%)$ & $43(11.1 \%)$ \\
Lack of technc & $182(47.2 \%)$ & $115(29.8 \%)$ & $58(15.0 \%)$ & $31(8.0 \%)$ \\
Poor power su] & $212(54.9 \%)$ & $155(40.2 \%)$ & $16(4.1 \%)$ & $3(0.8 \%)$ \\
Geographical 1 & $128(33.2 \%)$ & $115(29.8 \%)$ & $99(25.6 \%)$ & $44(11.4 \%)$ \\
Distraction b: & $86(22.3 \%)$ & $226(58.5 \%)$ & $45(11.7 \%)$ & $29(7.5 \%)$ \\
technological innovati & & & & \\
\hline
\end{tabular}

Source: Field Survey (2020)

Note: SA: Strongly agree, A: Agree, Disagree, SD: Strongly disagree

To cite this document:

Sulaiman, K. A. \& Akanbi, M. L. (2020). Perception of undergraduates on the contributions on online tools toward improvement of reading habit in Kwara state universities. Record and Library Journal, 6(2), 175- 188 Open access under Creative Commons Attribution-Non Commercial-Share A like 4.0 International Licence 
Table 8 shows response to the challenges of using online for reading with $109(28.2 \%)$ of the respondent strongly agreed with economic challenges as a challenge to the use of online tools for reading, $203(52.6 \%)$ of the respondent agreed while $31(8.0 \%)$ of the respondents disagreed and $43(11.1 \%)$ of the respondent strongly disagreed. This indicates that the majority of respondents agreed with economic challenges. 182 (47.25) of the respondents strongly agreed with the lack of technology know-how as challenge to using online tools, 115 (29.8\%) of the respondents agreed while $58(15.0 \%)$ of respondent disagreed and $31(8.0 \%)$ of the respondents strongly disagreed.

Moreover, $212(54.9 \%)$ of the respondents strongly agreed with power supply as a challenge to the use of online tools for reading, $155(40.2 \%)$ of the respondents agreed while $16(4.1 \%)$ of the respondent disagreed. This shows that the majority of respondents have strong opinions that poor power supply are part of a challenge to the use of online tools for reading. On the 128 (33.2\%) of the respondents strongly agreed with geographical local of students as challenge to the use of online for reading, 115 $(29.8 \%)$ of the respondents agreed while $99(25.6 \%)$ of the respondents disagreed and $44(11.4 \%)$ of the respondents strongly disagreed with geographical local of students as challenge to the use of online tools for reading.

It is also observed that $86(22.3 \%)$ of the respondents agreed with distraction by the fallout from technological innovation, majority of $226(58.5 \%)$ of the respondents agreed while $45(11.7 \%)$ of the respondents disagreed and $29(7.5 \%)$ of the respondents strongly disagreed to distraction by the fallout from technological innovation as challenge to use of online tools for reading. The implication of this table of the study shows that the majority of respondents agreed with economic, lack of technological knowhow, poor power supply, geographical location of students and distraction from fallout from technological innovation as challenges to the use of online tools for reading among undergraduates' in Kwara State.

Table 9. Benefits Of Using Online Tools For Reading

\begin{tabular}{lllll}
\hline Benefits & SA & A & D & SD \\
\hline Easy of accessibility & $123(31.9 \%)$ & $167(43.3 \%)$ & $68(17.6 \%)$ & $28(7.3 \%)$ \\
Improve knowledge & $92(23.8 \%)$ & $171(44.3 \%)$ & $68(17.6 \%)$ & $55(14.2 \%)$ \\
Improve research & $216(56 \%)$ & $87(22.5 \%)$ & $28(7.3 \%)$ & $55(14.2 \%)$ \\
Motivate reading & $121(31.3 \%)$ & $181(46.9 \%)$ & $30(7.8 \%)$ & $54(14.0 \%)$ \\
$\begin{array}{l}\text { Provision of infinite sources } \\
\text { of authentic materials }\end{array}$ & $133(34.5 \%)$ & $127(32.9 \%)$ & $65(16.8 \%)$ & $61(15.8 \%)$ \\
\hline
\end{tabular}

Source: Field Survey (2020)

Note: SA: Strongly agree, A: Agree, D: Disagree, SD: Strongly disagree

Table 9 shows the response to the benefits of using online tools for reading with $123(31.9 \%)$ of the respondents strongly agreed with easy accessibility, $167(43.3 \%)$ of the respondents agreed while 68 (17.6\%) of the respondents disagreed and 28 (7.3\%) of the respondents strongly disagreed. On the 92 $(23.8 \%)$ of the respondents strongly agreed with improved knowledge as benefits of online tools for reading, $171(44.3 \%)$ of the respondents agreed while $68(17.6 \%)$ of the respondents disagreed and 55 $(14.2 \%)$ of the respondents strongly disagreed.

Moreover, majority $216(56.0 \%)$ strongly agreed with improved research as benefits of using online tools for reading, $87(22.5 \%)$ of the respondents agreed while $28(7.3 \%)$ of the respondents disagreed and $55(14.2 \%)$ of the respondents strongly disagreed. On the $121(31.3 \%)$ of the respondents strongly agreed with motivating reading, 181 (46.9\%) of the respondents agreed while $30(7.8 \%)$ of the respondents disagreed and $54(14.0 \%)$ of the respondent strongly disagreed. $133(34.5 \%)$ of the respondent strongly agreed with provision of infinite sources of authentic materials, 127 (32.9\%) of the respondents agreed while $65(16.8 \%)$ of the respondent disagreed and $61(15.8 \%)$ of the respondents strongly disagreed with provision of infinite sources of authentic materials as benefits of using online tools for reading. The implication of this table of the study is that the majority of respondents agreed to ease of accessibility, 
improved knowledge, improve research, motivate reading and provision of infinite sources of authentic materials as benefits online tools to reading habit of undergraduates' in Kwara state.

\section{Results and Discussion}

The finding of the study shows that the majority of respondents agreed with use of blogs as an online tool used by undergraduates' for reading followed by Twitters, E-mail, Websites, You tubes, videos, Facebook and portal. This shows that the majority of respondents agreed with use of blogs, Twitters, Email as the most used online tools for reading while only a few respondents agreed to use of portals and networking sites as online tools for reading. The findings of this study are supported by Olatoye and Olatoye (2016) who identified social media as an online tool that influence undergraduates reading habits such as Facebook, blog, twitters, YouTube.

The study revealed that undergraduates in Kwara State have good perception in using videos, websites, blog, Twitters, YouTube, and E-mail as online tools for reading. This implies that undergraduates' in Kwara State have a very good perception about available online tools that could improve the reading habits of students. Obiozor-Ekeze, (2015) observed that the emergence of online tools has changed, re-echoed, and diversified the perception undergraduates' have about the online tools. Halic, Lee, Paulus and Spence (2010) supported the finding of this study that the majority of students found blogging to enhance their learning and noted that students with personal blogs were more interested in reading than students who did not have blogs as an online tool.

For the purpose of using online tools for reading majority of respondents agreed that the undergraduates' use online tools for social purpose followed by political, religion, economic, recreation, personal development and examination. This shows that majority of undergraduates' use online tools for social purpose, political and religious and only few respondents' use online tools for examination. This implies that most of undergraduates use online tools for reading using it for social purposes. This finding is supported by Mohammed Majid, Nalini and Ooichoon (2014) that the majority of students, regardless of gender and socio-economic status had the similar online reading habit and were more inclined toward social media activities than academic activity.

It is also found out that the majority of undergraduates often reading using online tools. This shows that the majority of respondents using online for reading among undergraduates' do it very often and only a few respondents rarely reading using online tools. The study also indicated that undergraduates use 1-3 hours on average for reading using online tools among undergraduates' in Kwara state. The findings of this study are supported by Shen, (2006) who indicated that the majority of respondents $(83.9 \%)$ read online information very often and other read using other sources.

The study also revealed that the majority of (undergraduates') agreed with economic challenges as problem to use of online tools for reading among undergraduates in Kwara State. It's also indicated in the study that lack of technological know-how, poor power supply, geographical location of students and distraction by the fallout from technological innovation are the challenges undergraduates encountered while using online tools for reading in the state. The findings of this study is corroborated the finding by Shelley-Robinson, (2001) which revealed that geographical setting of a student could also have an adverse effect on reading using online tools and stressed further that this challenge might be ascribed to Nigeria being a developing nation which had inadequate resources to acquire needed technologies.

It's also found out that the majority of respondents agreed with easy accessibility, knowledge improvement, research improvement, reading motivation and provision of infinite sources of authentic materials. This shows that undergraduates' in Kwara State use online tools for reading agreed that it improved their research, knowledge and sources of authentic materials. This is also supported by Samali, Humphrey, Clive and Kehbuma, (2015) that online tools is one of the most important motivations to read for students as it enables them to initiate reading even where other approaches have failed.

On the hypothesis tested, that there is no significant relationship between benefits of reading by undergraduates and the use of online tools in Kwara state. The finding indicated that "there is no significant relationship between benefits of reading by undergraduates' and using of online tools by 
undergraduates in Kwara State Universities is accepted." This is happening at benefits of reading and online tools variables correlated at 0.60 and greater than 0.05 levels of significance.

On the second hypothesis which stated that there is no significant difference between reading habit of undergraduates and use of online tools based on gender is rejected at level of significance 0.05 because $\mathrm{P}$-value is 0.02 is less than significance value and this shows that there is significant difference between reading habit of undergraduate and use of online tools based on gender.

\section{Conclusion}

Online tools or Information and Communication Technology have been established to a modern technology that found to be useful to all professions, specialization, areas and habit of all endeavors. Undergraduates in Kwara State University have indicated that the use of online tools created a good perception to their reading habit. This implies that undergraduates have good perception using online tools for their reading. However, the study concluded that undergraduate students using online tools are meant for social, political, recreation and religion benefits. It is also established that distraction, fallout from technologies, financial constraints and poor power supply are the major setbacks to the use of online tools for reading. The study, therefore, concluded that with online tools, knowledge, research, ease of accessibility and access to infinite sources of resources are the benefits of the use of online tools for reading among undergraduates in Kwara State.

\section{Recommendations for the Study}

Based on the discussion, and conclusion of the study, the following recommendations were made:

1. From the identified tools, the study recommended that undergraduates should carefully select online tools that would improve them in reading.

2. The study recommended that management should put in place tools that could make undergraduates development good perception about online tools.

3. The study also recommended that undergraduates should not make their precious time on online that could not improve their reading habit.

4. It was found out that undergraduates spend much time on online tools for social, political and religion purpose, so, it is therefore recommended that undergraduates should use online tools for examination reading.

5. The government and university management should provide stable power supply to undergraduate schools in Kwara State university. It is also recommended that library management authorities should make available online tools that would not only improve research but entrepreneurship skills.

\section{References}

Ajayi S A, Shorunke, O A \& Aboyade, M A. (2014). The influence of electronic resources use on students' reading culture in Nigerian Universities: a case study of Adeleke University Ede, Osun State. Library Philosophy and Practice (e-journal), 1-20.

Bradford, J. (2012). A case study examining the reading habits and self-regulated study habits of gifted readers in the context of deep reading, Dissertations, Theses and Capstone Projects. PhD Thesis, Bagwell College of Education, Kennesaw State University, USA.

Chettri K \& Rout S. K. (2013). Reading Habits - An Overview, Journal of Humanities and Social Science (IOSR-JHSS) 14(6), 13-17

Eta, O. Atarere, L. \& Rotua, A. O. (2015). The impact of information and communication technology (ICT) on learning habits of Business Education Students, International Journal of Innovative Education Research 3(4), 38-47.

Ewuzie, K, Vivian-Fowler College underscores the importance of reading. Available at www. Business day online .com, (Assessed on Oct, 2019).

Haliru R, Abdulkarim M, Mohammed A D \& Dangani B U. (2010). An assessment of reading habit among secondary school students in Kaduna Metropolis,IOSR Journal of Humanities and Social Science 
(IOSR-JHSS), 20(10), 12-17.

Halic, O. Lee, D. Paulus T \& Spence, M. (2010). To blog or not to blog: Student perceptions of blog effectiveness for learning in a college-level course, The Internet and Higher Education, 13(4), 206-213.

Hetting, H. \& Knapp, H. (2001). Beyond Motivation: ESL/ EFL Teachers' Perceptions of the Role of Computers. CALICO Journal, 25(2), 241-259.

Ihuoma, H. I. (2012) Students' perceptions of the contributions of ICTS towards reading culture among university undergraduate students in Edo state. A project submitted to the department of library and information science in partial fulfillment of the requirements for the award of Master of Library Science (MLS) In Library and Information Science department of Library and Information Science University of Nigeria, Nsukka.

Issa, A. O, Amusan, B. B. Adeniran C O, \& Bolarinwa, L. (2014). Perception of university undergraduate students on the effects of exposure to ICT on their reading habits: The Kwara State Experience, International Journal of Digital Library Services, 4(3), 20-33.

Izabela, O. (2015). The effect of online tools on reading habits among teenage students. Model of chances and dangers, English for Specific Purposes World, 45(16) (2015), 1-12

Kazim D.T. (2019). Reviving Reading culture in Nigeria. Available at Almasculture.hubpages. / Com/ (Assessed on August, 2019).

Jönsson, A. \& Olsson, J. (2008). Reading culture and literacy in Uganda: The case of the Students' Reading Tent, Master's thesis, HögskolanIborås Vetenskapför Profession.

Loan A. F. (2019). Reading habits of rural and urban college students in 21st Century. Available at "http://www.webpages" uidaho.edu, (Assessed on July, 2019).

Muhlise, C. Ö. \& Esin, A. (2009). Investigating reading habits and preferences of student teachers at foreign language departments. The International Journal of Language Society and Culture, 28,7279.

Palani K. K. (2012). Promising reading habits and creating literate social. International Reference Research Journal, 2(1), 91-111

Samali V M, Humphrey M S, Clive K T, Kehbuma L, Kehbuma, L, Victor, WA and Mayok, K. K, (2014).Towards an Improved Reading Habit of University Students: The Impact of ICT. Conference Papers Malaysia 23-25 January, 102-116.

Satija, M..P. (2002) Reading and book culture, Herald of Library Science, 41(1) (2002) 76-87

Siraj-Blatchford, J., and Siraj-Blatchford D. (2003). Supporting Information and Communications Technology in the early years. $3^{\text {rd }}$ edn (Berkshire: Open University Press), 23-43.

Shahnil, A. \& Zaliffah, A. (2014). The impact of digital-based materials on undergraduates' reading habit. International Journal of Social Science and Humanity, 4(3), 249-253.

Shen, L. B. (2006). Computer technology and college students' reading habits. Chia-Nan Annual Bulletin, 32,559-572. 